\title{
Evaluation of Tree Species for Agroforestry Practice on Entisols in the Sudan Sahel Region of Nigeria
}

\author{
Ioryisa Verinumbe \\ College of Forestry and Fisheries, University of Agriculture Makurdi, Nigeria
}

Copyright $\bigcirc 2017$ by authors, all rights reserved. Authors agree that this article remains permanently open access under the terms of the Creative Commons Attribution License 4.0 International License

\begin{abstract}
Background: Evaluation of Acacia nilotica, Acacia Senegal, Azadirachta indica, Eucalyptus camaldulensis, Khaya senegalensis, Leucaena leucocephala and Prosopis juliflora for growth and interactions with soil and crops for agroforestry development was undertaken on Entisols in the Sudan Sahel region of North Eastern Nigeria. One hundred trees of each species were established at $2 \times 2 \mathrm{~m}$ spacing on a sandy loam entisol by intercropping with beans (Vigna unguiculata) for the initial 2 years. Tree growth was regularly recorded and changes in soil properties as well as yield of Sorghum vulgare on them also evaluated. 2) Results: The tree species recorded more than $60 \%$ survival and grew rapidly. The highest annual mean tree girth growth rate of $3.65 \mathrm{~cm}$ occurred in Leucaena leucocephala, followed by Acacia nilotica $(3.61 \mathrm{~cm})$, Azadirachta indica $(3.01 \mathrm{~cm})$, Eucalyptus camaldulensis $(2.78 \mathrm{~cm})$, Khaya senegalensis $(2.72 \mathrm{~cm})$, Acacia Senegal $(2.55 \mathrm{~cm})$ and Prosopis juliflora $(2.23 \mathrm{~cm})$. The trees accumulated sand and improved nutrient status of the soil under them. Sorghum vulgare crop grown on the forest soils produced higher dry matter yield than the surrounding field soil. The best crop yield of $3.22 \mathrm{~g} / \mathrm{plant}$ occurred on Leucaena leucocephala soil, followed by Azadirachta indica (2.92 g/plant), Acacia nilotica (2.33 g/plant), Eucalyptus camaldulensis (2.22 g/plant), Prosopis juliflora (1.80 g/plant), Acacia Senegal (1.71 g/plant), the control (1.59 g/plant) and Khaya senegalensis (1.22 g/plant). 3) Conclusions: The study ranked species according to their growth and agroforestry qualities. It also observed some inter-tree species interactions which, when fully developed, will be very useful for scientific management of mixed species tropical agroforests.
\end{abstract}

Keywords Trees Evaluation, Agroforestry Practice, Entisols, Sudan Sahel Nigeria

\section{Background}

Among the predominantly rural farmers in the West
African Sudan Sahel region, naturally regenerated trees are the major source of domestic wood, medicinal extracts, supplementary food, dry season feed, and soil replenishment (Barrott [1], Verinumbe [2] and Hubert [3]). As a result of inadequate management, the trees have low productivity, and, according to N.A.S. [4], they cannot adequately meet the present demand for their goods and services. They are therefore over-exploited leading to ecosystems degradation, desertification and further reduction in productivity (Glantz [5], U.N. [6]).

To improve tree regeneration and growth and to conserve the environment in order to increase food and wood production on sustained basis, De Troyer [7], Maydell [8], King [9], Huxley [10, 11] and Verinumbe [2] suggested the sequential and simultaneous planting of fast growing, soil rejuvenating and socio-economically accepted trees with crops. However, in the West African Sudan Sahel region, a major problem hindering the development of the technical packages for successful implementation of this is the lack of systemic information on the potential tree species. The present study had the objective to contribute to the resuscitating qualities of four exotics and three local potential farm tree species in a Sudan Sahel region of North Eastern Nigeria. The exotics include Eucalyptus camaldulensis, Leucaena leucocephala, Azadirachta indica and Prosopis juliflora while the indigenous ones include Acacia nilotica, Acacia Senegal and Khaya senegalensis.

\section{Materials and Methods}

The study site was an abandoned farm land on the outskirts of Maiduguri town in the Sudan Sahel region of North Eastern Nigeria $\left(11^{0} 53^{\prime} \mathrm{N}, 13^{0} 16^{\prime} \mathrm{E}\right)$. The mean annual rainfall for the past 30 years was $589.07 \pm 148.47 \mathrm{~mm}$. Mean monthly temperatures were $26.78^{\circ} \mathrm{c}$ while daily evaporation was $5.23 \pm 1.03 \mathrm{~mm}$. The soil was a sandy loam entisol described by Klinkenberg and Higgins [12] as a juvenile soil on Aeolian sands.

About half a hectare available land was demarcated into seven plots of $20 \times 20 \mathrm{~m}$ each. Seedlings of the seven species 
were raised in polythene pots at the nursery. After 3 months, the seedlings were planted out on the plots in pure stands at 2 $\mathrm{x} 2 \mathrm{~m}$ spacing. Where species shared boundary, the between plot spacing was also $2 \mathrm{~m}$. Each plot therefore contained 100 trees of a single species. Since the available land was very small and largely uniform, the experiment was not replicated. In addition to weeding and intercropping with beans (Vigna unguiculata) during the first 2 years, the trees were also given supplementary irrigation during the first dry season.

Total number of surviving trees in each plot was counted and percent tree survivals determined after the trees had grown for 66 months. Collar girths of the centrally located trees in each plot were measured at age intervals of $3,15,33$, 45 and 66 months and compared.

On visual observation in the fourth year that boundary trees from species that shared common boundary and had both intra and inter plot spacing of $2 \mathrm{~m}$ grew differently from other ones, a quantitative assessment was made. Girths of the affected boundary trees were measured and compared with tree of the same species that grew at the centre of the plot.

Also, in the fourth year of the experiment, composite surface $(0-15 \mathrm{~cm})$ soil samples taken and mixed from 5 stratified random locations under each of the tree species plantations were analysed for some of their physical and chemical properties. Soil samples similarly taken and analyzed from the surrounding natural fallow field were the control against which the soils from the forest plantations were compared. Soil samples similarly taken were used to grow a local variety of Sorghum (Sorghum vulgare) in pots, under nursery conditions. The soil from each tree species plantation (and the control) was replicated in 10 pots. The pots from all the tree plantations, including the control, were randomly arranged and similarly managed. After eight weeks growth, total aerial dry biomass yields as well as nutrient content of the sorghum crops were determined. Variability of the crop yield data among the tree species and control was finally tested using the analysis of variance and Duncan's multiple range tests.

\section{Results and Discussions}

\section{Tree Survival and Growth}

The survival rates and growth data on tree species are presented in Tables 1-3. The indigenous Acacia nilotica and Acacia Senegal demonstrated superior survival qualities by recording over $95 \%$ survival. They were followed by the exotic Prosopis juliflora, Leucaena leucocephala and Azadirachta indica. Although Khaya senegalensis is a local species it is naturally more adapted to areas more humid than the Sudan Sahel. This may explain its relatively low survival $(76 \%)$ which was still better than the exotic Eucalyptus camaldulensis (59\%).

Mean girths of the tree species (Table 1) increased from $2.61 \mathrm{~cm}$ in the first 12 months to $19.82 \mathrm{~cm}$ at the end of 66 months giving mean annual increment of about $3.3 \mathrm{~cm}$. Acacia nilotica recorded the largest final girth $(24.42 \mathrm{~cm})$ followed by Leucaena leucocephala $(22.58 \mathrm{~cm})$, Azadirachta indica $(21.17 \mathrm{~cm})$, Khaya senegalensis $(18.88 \mathrm{~cm})$, Eucalyptus camaldulensis $(18.33 \mathrm{~cm})$, Acacia Senegal $(17.14 \mathrm{~cm})$, and Prosopis juliflora $(16.25 \mathrm{~cm})$.

Current annual and mean (estimated by regression analysis) growth rates are presented in Table 2. It indicates that very rapid current annual growth occurred in the first two years, decreasing from $10.42 \mathrm{~cm}$ in the first year to $9.35 \mathrm{~cm}$ in the second one. This was probably aided by the supplementary dry season irrigation in the first year and intercropping with beans (Vigna unguiculata) during the two years. Cessations of intercropping and lower rainfall were associated with further decline in tree growth rates in the third and fourth years respectively. With improved rainfall in the final year and possibly recovery from shock due to cessation of irrigation and intercropping, tree growth rates improve but were still lower than those of the first two years. The differences between the third, second and first year growths respectively, gives some indication of the effects of intercropping and irrigation as well as age.

Table 1. Girth development (cm/tree) of tree species, at different ages (months), on entisols in the Sudan Sahel region of Nigeria.

\begin{tabular}{|c|c|c|c|c|c|c|}
\hline \multirow{2}{*}{ Tree Species } & \multicolumn{5}{|c|}{ Mean tree girth $(\mathrm{cm} /$ tree) at various ages (months): } & \multirow{2}{*}{ Tree Survival (\%) } \\
\hline & 3 & 15 & 33 & 45 & 66 & \\
\hline L. Leucocephala & 3.21 & 11.69 & 18.56 & 19.65 & 22.58 & 87 \\
\hline A. Senegal & 2.29 & 11.81 & 16.43 & 16.51 & 17.14 & 97 \\
\hline P. Juliflora & 2.66 & 11.84 & 14.47 & 14.84 & 16.24 & 93 \\
\hline K. Senegalensis & 1.96 & 13.81 & 16.62 & 16.69 & 18.88 & 76 \\
\hline A. Nilotica & 2.95 & 13.84 & 16.62 & 18.64 & 24.42 & 99 \\
\hline E. Camaldulensis & 1.88 & 8.5 & 11.14 & 11.88 & 18.33 & 59 \\
\hline A. Indica & 3.29 & 12.13 & 14.43 & 16.15 & 21.17 & 81 \\
\hline Mean & 2.61 & 11.69 & 15.48 & 16.34 & 19.82 & 84.57 \\
\hline
\end{tabular}


Table 2. Current annual growth (cm/tree) of tree species, at different ages (months), on entisols in the Sudan Sahel region of Nigeria.

\begin{tabular}{|c|c|c|c|c|c|c|c|}
\hline \multirow{2}{*}{ Tree Species } & \multicolumn{5}{|c|}{ Mean tree girth $(\mathrm{cm} /$ tree) at various ages (months): } & \multirow{2}{*}{ Mean } & \multirow{2}{*}{ L. Reg slope } \\
\hline & 3 & 15 & 33 & 45 & 66 & & \\
\hline L. Leucocephala & 12.84 & 8.48 & 4.64 & 1.00 & 1.67 & 5.73 & 3.65 \\
\hline A. Senegal & 9.16 & 9.52 & 3.08 & 0.08 & 0.63 & 4.49 & 2.55 \\
\hline P. Juliflora & 10.64 & 9.28 & 1.69 & 0.37 & 0.81 & 4.56 & 2.23 \\
\hline K. Senegalensis & 7.48 & 11.85 & 1.87 & 0.07 & 1.25 & 4.58 & 2.72 \\
\hline A. Nilotica & 11.80 & 10.89 & 1.85 & 2.02 & 3.30 & 5.97 & 3.61 \\
\hline E. Camaldulensis & 7.52 & 6.62 & 1.76 & 0.74 & 3.69 & 4.07 & 2.78 \\
\hline A. Indica & 13.16 & 3.34 & 1.53 & 1.72 & 2.87 & 5.62 & 3.01 \\
\hline Mean & 10.42 & 9.35 & 2.35 & 0.86 & 2.03 & 5.00 & 2.94 \\
\hline Rainfall (mm). & 393.42 & 520.10 & 742.10 & 314.50 & 525.07 & 499.04 & \\
\hline
\end{tabular}

Table 3. Variation in girths $(\mathrm{cm} /$ tree) of 48 months old boundary trees under the influence of neighbouring trees of other species.

\begin{tabular}{|c|c|c|c|c|}
\hline Affecting Species & $\begin{array}{c}\text { Affected species girth } \\
\text { (cm/tree) }\end{array}$ & & \\
\hline & L. leucocephala & A. Nilotica & E. Camaldulensis & A. indica \\
\hline L. leucocephala & 0.00 & 3.63 & $*$ & 2.81 \\
\hline A. nilotica & -30.83 & 0.00 & 0.89 & $*$ \\
\hline E. camaldulensis & $*$ & -3.37 & -2.46 & -3.97 \\
\hline A. indica & -4.04 & $*$ & 0.00 \\
\hline
\end{tabular}

* indicates species not sharing boundary.

Mean annual girth increment of $3 \mathrm{~cm}$ implies very rapid growth, especially when compared with $2-3 \mathrm{~cm}$ reported for similar species by NAS [13]. While regression analysis of the girth growth data indicates that the fastest growing species was Leucaena leucocephala, all other estimates suggested the superiority of Acacia nilotica. After initial slow growth, Acacia nilotica girth increased rapidly and was the largest by the final year. Azadirachta indica and Khaya senegalensis followed the pattern of growth of Acacia nilotica and ranked third and fourth respectively. The rest of the species including Acacia Senegal and Prosopis juliflora in decreasing order of magnitude grew slower and had smaller girths. The low rating of Acacia Senegal and Prosopis juliflora in this study does not necessarily imply low total dry matter production by the two species. Their shrubby nature when young and therefore lack of clear boles might have also contributed to their low rating since girth was used as a parameter for the evaluation. This is a major problem in the evaluation of dry savannah species. The low survival rate and therefore low stocking density of Eucalyptus camaldulensis might have also given it some growth advantage over other species.

\section{Species Interactions}

Table 3 gives an estimate of the changes in tree girth by species that shared a common boundary. Species that grew near the non-legumes, Azadirachta indica and Eucalyptus camaldulensis exhibited slow growth as indicated by the negative differences between girths of their boundary and centrally located trees. The two species however benefited by their association with the legumes, Leucaena leucocephala and Acacia nilotica, and improved girth growth by $2.18 \mathrm{~cm}$ and $2.98 \mathrm{~cm}$ respectively. The legume Leucaena leucocephala grew slower $(-3.83 \mathrm{~cm})$ under the influence of another legume, Acacia nilotica. The interactions between two non-legumes, Eucalyptus camaldulensis and Azadirachta indica resulted in decreased girth growth of both species.

It is possible that the non-legumes gained nitrogen from the legumes and grew faster while legumes lost same and grew slower. Between legumes, the indigenous Acacia nilotica was probably more competitive, less nitrogen fixing (Table 4) and therefore gained by its interaction with the exotic Leucaena leucocephala which subsequently suffered by a decreased growth. Similarly competition for limited soil resources was probably responsible for slow girth growth of both Azadirachta indica and Eucalyptus camaldulensis where the two non-legumes interacted.

\section{Soil Changes}

Changes in properties of soil under the tree plantations when compared with the surrounding natural fallow field are presented in Table 4 . The results indicate that the plantations gained sand and lost clay. They also became more acidic and accumulated soil nitrogen, potassium and calcium.

The decline in clay and increase in sand might be as a result of either the trapping of wind-blown sand by the trees or changes in the behaviour of surface water under the trees. Since sand particles are heavier than clay particles, they require stronger winds to erode them over long distances. The presence of trees might have reduced wind speed and either prevented the removal or caused the deposition of the more heavy sand particles. The trees might have also improved water infiltration in the soil under them and therefore increased eluviations of the lighter suspended clay particles. All these could have led to increase in sand and decrease in clay content of surface soil under the trees. Further study of the lower soil horizons is necessary to 
identify more clearly which of the factors was responsible.

The soil under all the legumes except Acacia nilotica ranked high in nitrogen content. Leucaena leucocephala accumulated the highest amount, followed by Acacia Senegal, Prosopis juliflora, Azadirachta indica, Khaya senegalensis, Acacia nilotica and Eucalyptus camaldulensis. The highest amount of potassium was accumulated by Acacia nilotica whose soil was also the second most acidic after that of Azadirachta indica. Litter decomposition, reduced soil erosion, improved soil microbial activity and higher concentrations of organic compounds were possibly responsible for the gains in surface nutrients and activity under the trees.

\section{Sorghum Yield}

Data on yield characteristics of Sorghum vulgare grown in pots on surface soil sampled under the tree plantations are presented in Tables 5 and 6 . Soil from Leucaena leucocephala which had the highest amount of nitrogen also produced the best crop yield. This was followed by soil from Azadirachta indica which also had fairly high nitrogen and potassium content. Although Acacia nilotica soil had relatively low nitrogen content, it produced the third best crop yield. This was probably due to the high amount of potassium which it contained. Except perhaps for the very low phosphorus content of the crop from Khaya senegalensis soil, nutrient content of the crop yields did not show peculiar features of major interest. They however gave an indication of how much the soil can be depleted of nutrients if the trees are cleared and cropped.

Table 4. Differences between properties of soil inside and outside (control) plantations of tree species in the Sudan Sahel region of Nigeria

\begin{tabular}{|c|c|c|c|c|c|c|c|}
\hline Tree Species & Sand (\%) & Silt (\%) & Clay (\%) & N (\%) & K(ppm) & Ca (ppm) & $\mathrm{P}^{\mathrm{H}}$ \\
\hline $\begin{array}{c}\text { L. } \\
\text { Leucocephala }\end{array}$ & 8.98 & -2.21 & -2.53 & 0.136 & 31 & 795 & 0.11 \\
\hline A. Senegal & 4.45 & 1.16 & -4.10 & 0.100 & 2 & 408 & 0.05 \\
\hline P. Juliflora & 3.96 & 3.78 & -3.74 & 0.100 & 12 & -41 & 0.04 \\
\hline K. Senegalensis & 3.99 & 1.50 & -2.49 & 0.044 & 2 & 408 & 0.05 \\
\hline A. Nilotica & 3.98 & 2.77 & -3.75 & 0.018 & 60 & 285 & 0.23 \\
\hline $\begin{array}{c}\text { E. } \\
\text { Camaldulensis }\end{array}$ & 5.77 & -2.68 & -0.09 & 0.014 & 7 & 897 & 0.01 \\
\hline $\begin{array}{c}\text { A. Indica } \\
\text { Control } \\
\begin{array}{c}\text { Mean } \\
\text { Differences }\end{array}\end{array}$ & 6.48 & 1.58 & -5.00 & 0.081 & 12 & 571 & 0.23 \\
\cline { 2 - 9 } & 0.0 & 0.0 & 0.0 & 0.0 & 0.0 & 0.0 & 0.00 \\
\hline
\end{tabular}

Table 5. Yield characteristics of Sorghum vulgare grown for 2 months in pots on soil under 4 year old plantations of tree species in the Sudan Sahel region of Nigeria.

\begin{tabular}{|c|c|c|c|c|c|c|c|}
\hline \multirow{2}{*}{ Tree Species } & \multicolumn{7}{|c|}{ Sorghum yield Characteristics } \\
\cline { 2 - 9 } & Biomass & \multicolumn{7}{|c|}{ Nutrient content } \\
\cline { 2 - 9 } & $\mathbf{( g / p l a n t )}$ & $\mathbf{N}$ & $\mathbf{P}$ & $\mathbf{K}$ & $\mathbf{C a}$ & Mg & Na \\
\cline { 2 - 9 } & & $\mathbf{( \% )}$ & $\mathbf{( p p m )}$ & $\mathbf{( p p m )}$ & $\mathbf{( p p m )}$ & $\mathbf{( p p m )}$ & $\mathbf{( p p m )}$ \\
\hline L. Leucocephala & $3.22 \pm 1.44$ & 3.22 & 32.5 & 32.0 & 204.0 & 24.3 & 11.2 \\
\hline A. Senegal & $1.71 \pm 1.28$ & 3.22 & 3.20 & 40.0 & 326.0 & 48.6 & 11.0 \\
\hline P. Juliflora & $1.80 \pm 1.18$ & 2.94 & 32.5 & 41.0 & 286.0 & 72.9 & 12.2 \\
\hline K. Senegalensis & $1.22 \pm 0.55$ & 2.38 & 20.0 & 41.5 & 204.0 & 24.3 & 12.2 \\
\hline A. Nilotica & $2.33 \pm 1.00$ & 2.66 & 37.5 & 44.0 & 244.8 & 72.9 & 12.5 \\
\hline E. Camaldulensis & $2.22 \pm 1.60$ & 2.50 & 32.5 & 40.0 & 204.0 & 24.3 & 12.0 \\
\hline A. Indica & $2.93 \pm 1.26$ & 2.38 & 40.0 & 44.8 & 163.0 & 24.3 & 14.0 \\
\hline Control & $1.59 \pm 0.50$ & 2.66 & 35.0 & 38.0 & 122.4 & 24.3 & 11.5 \\
\hline
\end{tabular}


Table 6. Comparative differences in Biomass (g/plant) of Sorghum vulgare grown for two months in pots on soil under tree species plantations in the Sudan Sahel region of Nigeria

\begin{tabular}{|c|c|c|c|c|c|c|c|}
\hline & L. Leuc. & A. Seneg. & P. Juli. & K. Seneg. & A. Nilot. & E. Camal. & A. Indic. \\
\hline L. Leuc & - & - & - & - & - & - & - \\
\hline A. Seneg & $1.51^{*}$ & - & - & - & - & - & - \\
\hline P. Juli & $1.42^{*}$ & 0.08 & - & - & - & - & - \\
\hline K. Seneg & $2.00^{*}$ & 0.49 & 0.58 & - & - & - & - \\
\hline A. Nilot & 0.89 & 0.62 & 0.53 & $1.11 *$ & - & - & - \\
\hline E. Camal & $1.11^{*}$ & 0.39 & 0.31 & 0.89 & - & - & - \\
\hline A. Indic & 0.29 & $1.22^{*}$ & $1.13^{*}$ & $1.71 *$ & 0.60 & -0.82 & - \\
\hline Control & $1.63^{*}$ & 0.12 & 0.21 & 0.37 & 0.74 & 0.52 & $1.34 *$ \\
\hline $\begin{array}{c}\text { Mean yield } \\
\text { (g/plant) }\end{array}$ & 3.22 & 1.71 & 1.8 & 1.22 & 2.33 & 2.11 & 2.93 \\
\hline
\end{tabular}

$*=$ Statistical significance $(\mathrm{p}<0.05)$ of the difference in Sorghum yield on soil from the 2 compared species plantations.

Comparison of the yield from the tree species plantation (Table 6) indicate that soil from Leucaena leucocephala and Azadirachta indica produced significantly $(\mathrm{P}<0.05)$ higher crops yield than soil from the control, Acacia Senegal, Prosopis juliflora, Khaya senegalensis and Eucalyptus camaldulensis. The lowest crop yield of $1.22 \mathrm{~g} / \mathrm{plant}$ produced on soil from Khaya senegalensis plantation was statistically the same $(p<0.05)$ as those produced on the soil from Eucalyptus camaldulensis and the control. The indication of the result that Leucaena leucocephala followed by Azadirachta indica, Acacia nilotica, Eucalyptus camaldulensis, Prosopis juliflora and Khaya senegalensis improved crop yield is important for the development of sustainable agroforestry systems for the Sudan Sahel region (Raintree [14]). What needs priority attention is a more clear identification of the soil and tree attributes that were conclusively responsible for the variability in the crop yields on soil under the various tree species.

\section{Conclusions}

Results from the present study have many implications for agroforestry and forestry development in the region. The successful and leading performance of Leucaena leucocephala, an acknowledged agroforestry species, will continue to provide a basis for comparative evaluation and development of the indigenous multipurpose tree species. The indigenous Acacia nilotica for example grew as fast as Leucaena leucocephala and contributed substantially to soil development and crop yield. The indigenous species are already adapted and are of substantial importance to the area. As they produce wood, feed, gum Arabic, tannin and medicinal extracts, any additional knowledge about their crop yield improving qualities will further promote their usefulness.

The indication that intercropping non-legumes with legume trees can enhance the growth of the former is also of great importance in the dry zone forest management. The region is dominated by 'slow' growing leguminous trees, which can be used as nurse trees for rapid production of desirable non-legume trees. It also implies that when combining species in mixed plantations, adequate care should be taken to mix only those species that have positive effects on the target species.

Another very important aspect of the study is its service as a basis for further investigation to test and rank the species in more properly designed experiments, so as to obtain more complete information about factors that determine their growth rates, and soil ameliorating qualities.

\section{Competing Interests}

The author declares that there are no competing interests in the manuscript.

\section{REFERENCES}

[1] Barrott H.N (1972) Fuel wood supplies in Kastina Province. The Nigeria Journal of Forestry 2(2):62-66.

[2] Verinumbe, I. (1989). Agroforestry development in North-Eastern Nigeria. International Conference on Agroforestry Principles and Practices. 23-28 July, 1989, Edinburgh University, U.K.

[3] Hubert Gillet (1980): Observations on the causes of devastation of igneous plants in the Sahel and their resistance to destruction: in: la Houerou, H.N. (ed) Browse in Africa the current state of Africa, Addis Ababa, Ethiopia 1980.

[4] National Academy of Sciences (1977) Leucaena: a promising forage and tree crop for the tropics, NAS Washington DC. 1977. Pp.115.

[5] Glantz, Michael H. (1987), African drought and its impacts: reviewed interests in a recurrent phenomenon. In: UNEP (1987) Desertification.

[6] United Nation Organizations (1978) United Nations Conference on Desertification. 29 Aug - 9 Sept. 1977. U.N.S, N.Y. 1978 pp43. 
[7] De Troyer, C. (1986) Desertification control on the Sudanian and Sahelian zones of West Africa - Better management of the renewable resources base. Forest Ecology and management (1986): 233-241.

[8] Von Maydell, H.J. (1978) Tree and shrub species for Agroforestry systems in the Sahelian zone of Africa. Plant Research and Development. Vol.7: 44-8.

[9] King, K.F.S (1979), Agroforestry and Fragile ecosystems. In Mongi, H.O. and P.A. Huxely (Eds) Soils research in agroforestry- proceedings of an expert consultation. ICRAF, Nairobi, Kenya. March 26-30 1979.

[10] Huxely, P.A. (1983) Some Characteristics of trees to be considered in agroforestry. Plant Research and Agroforestry.
ICRAF Reprints No. 10: 3-12.

[11] Huxely, P.A. (1984) The role of trees in agroforestry: some comments. ICRAF reprints No. 10:257-270.

[12] Klinkenberg K. And Higgins, G.M. (1970), An outline of Northern Nigeria soils. Samaru Research Bulletin 107. Institute of Agricultural Research, Samaru, Zaria, Nigeria. $115 \mathrm{pp}$.

[13] National Academy of Sciences (1980) Firewood crops: Shrub and tree species for energy production. NAS, Washington D.C. 1980 pp237.

[14] Raintree J.B. (1984) Bio-economic considerations in the design of Agroforestry cropping systems. ICRAF Reprint No. 11: 271-289. 